\title{
PERIPHERALLY INSERTED CENTRAL CATHETERS IN ORTHOPEDIC PATIENTS: EXPERIENCE FROM 1023 PROCEDURES
}

\section{CATETER CENTRAL DE INSERÇÃO PERIFÉRICA EM PACIENTES ORTOPÉDICOS. EXPERIÊNCIA EM 1023 PROCEDIMENTOS}

\author{
Thais Queiroz Santolim ${ }^{1}$, André Mathias Baptista ${ }^{2}$, Arlete Mazzini Miranda Giovani ${ }^{1}$, Juan Pablo Zumárraga ${ }^{2}$, \\ Olavo Pires de Camargo 2,3
}

1. Departement of Nursing, Institute of Orthopedics and Traumatology, Hospital das Clinicas (HCFMUSP), Faculdade de Medicina, Universidade de São Paulo, São Paulo, SP, Brazil. 2. Orthopedic Oncology Group, Institute of Orthopedics and Traumatology, Hospital das Clinicas (HCFMUSP), Faculdade de Medicina, Universidade de São Paulo, São Paulo, SP, Brazil. 3. Department of Orthopedics and Traumatology, Hospital das Clinicas (HCFMUSP), Faculdade de Medicina, Universidade de São Paulo, São Paulo, SP, Brazil.

\section{ABSTRACT}

Objectives: The advantages of using a peripherally inserted central catheter (PICC) in hospitalized patients make this device very important for intravenous therapy. This study describes the use of PICCs at the Institute of Orthopedics and Traumatology at the Hospital das Clinicas da Faculdade de Medicina da Universidade de São Paulo over the last 10 years. Methods: This retrospective study analyzed 1,057 medical records and included 1,023 medical files with complete information on the punctured vein, diagnosis, duration of catheterization, complications, and catheter tip positioning. Results: Seven hundred and twenty PICCs (70.4\%) were considered successfully positioned, and mean duration of catheterization was 34.3 days. The basilic vein was used in 528 (51.6\%) patients, while 157 (15.4\%) catheters were removed due to complications. No cases of catheter-related thrombosis or infection were found. Eight hundred and sixty-six (84.6\%) patients completed their treatment with PICC in place. Conclusion: PICC is a safe intravenous device that can be successfully utilized for medium- and long-course intravenous therapy in hospitalized and discharged orthopedic patients. Level of Evidence IV; Case series.

Keywords: Catheterization, central venous. Catheterization, peripheral. Infusions, intravenous. Nursing care.

\section{RESUMO}

Objetivos: As vantagens da utilização do Cateter Central de Inserção Periférica (CCIP) no ambiente hospitalar faz com que esse cateter ocupe uma posição de destaque na terapia intravenosa. Este trabalho relata o uso do CCIP nos pacientes do Instituto de Ortopedia e Traumatologia do Hospital das Clinicas da Faculdade de Medicina da Universidade de São Paulo (IOT-HC-FMUSP) nos últimos 10 anos. Métodos: Trata-se de um estudo retrospectivo, no qual foram analisados 1057 prontuários. Foram incluídos 1023 prontuários de pacientes submetidos à inserção do CCIP, em que foram analisados a veia puncionada, diagnóstico do paciente, tempo em que o paciente permaneceu com o cateter, complicações e posicionamento da ponta do CCIP. Resultados: Setecentos e vinte CCIPs $(70,4 \%)$ foram considerados adequadamente posicionados. 0 tempo médio de utilização do cateter foi de 34,3 dias. A veia basílica foi a mais utilizada em 528 (51,6\%) pacientes. Cento e cinquenta e sete $(15,4 \%)$ cateteres foram removidos devido a complicações. Nenhum caso de trombose ou infecção relacionada ao cateter foi observada. Oitocentos e sessenta e seis (84,6\%) permaneceram com o CCIP até o final do tratamento. Conclusão: O CCIP é um dispositivo intravenoso seguro e pode ser utilizado para terapia intravenosa de média e longa duração em pacientes ortopédicos hospitalizados ou desospitalizados. Nível de Evidencia IV; Série de casos.

Descritores: Cateterismo venoso central. Cateterismo periférico. Infusões intravenosas. Cuidados de enfermagem.

Citation: Santolim TQ, Baptista AM, Giovani AMM, Zumárraga JP, Camargo OP. Peripherally inserted central catheters in orthopedic patients: experience from 1023 procedures. Acta Ortop Bras. [online]. 2018;26(3):206-10. Available from URL: http://www.scielo.br/aob.

\section{INTRODUCTION}

Peripherally inserted central catheter (PICC) is the gold standard device for prolonged intravenous therapy and its use is constantly growing. Some of the PICCs benefits are: the ability to maintain prolonged therapy with fewer vein punctures, the low incidence of infection, the possibility to insert this device at bedside, the possibility to administer parenteral nutrition with dextrose concentration greater than $10 \%$, vesicant, irritant, vasoactive drug and solutions with extreme osmolarity or non physiological $\mathrm{pH}^{1-3,4,5-7} \mathrm{PICC}$ began to be used in Brazil in the early 1990s, initially in neonatal patients. ${ }^{5}$ Its use quickly expanded to patients of all ages due to its advantages over other central venous catheters, including reduced risk of pneumothorax and sepsis resulting from colonization of the skin around the insertion point, lower insertion costs compared with other central venous

All authors declare no potential conflict of interest related to this article.

Work conducted at the Institute of Orthopedics and Traumatology, Hospital das Clinicas (HCFMUSP), Faculdade de Medicina, Universidade de São Paulo, São Paulo, SP, Brazil. Correspondence: Juan Pablo Zumárraga. Rua Ovídio Pires de Campos, 333, Cerqueira Cesar, São Paulo, SP, Brazil. 05403-010. juanpzumarraga@hotmail.com 
catheters, easy maintenance, and the ability to discharge patients while still continuing antibiotic therapy and chemotherapy. ${ }^{1,8,9}$ For the PICC to function properly as a central line, it is critical that the tip be properly positioned in the central circulation. When the puncture is performed in the arms, the basilic and the cephalic veins are recommended for insertion. PICC can be inserted via direct puncture, also known as blind puncture or with the aid of ultrasound (US), using the modified Seldinger technique. The tip is positioned using an anatomical measurement which is made before starting the procedure. Improper positioning of the tip in the vascular system is associated with a significant increase in malfunction of the device, fibrin formation, and venous thrombosis. When the tip of the catheter is located in the lower portion of the right atrium or right ventricle, it may cause arrhythmias, tricuspid valve dysfunction, erosion, or atrial thrombosis. The tip of the catheter may also be inadvertently placed in the subclavian vein, jugular vein, or other thoracic veins. This type of poor positioning is consistently associated with pain during infusion, device malfunction, or venous thrombosis. ${ }^{10,11}$ To confirm the position of the catheter tip, a chest $x$-ray is required at the end of the procedure. (Figures 1 and 2) Variations in image interpretation may occur due to anatomic abnormalities or in obese patients. Other forms of verifying the placement of the catheter tip using fluoroscopy and electrocardiogram (ECG) are being incorporated into the procedure to assure correct positioning. ${ }^{10,12,13}$ The objective of this study is to evaluate whether PICC is safe and suitable for medium- and long-term intravenous therapy in orthopedic patients.

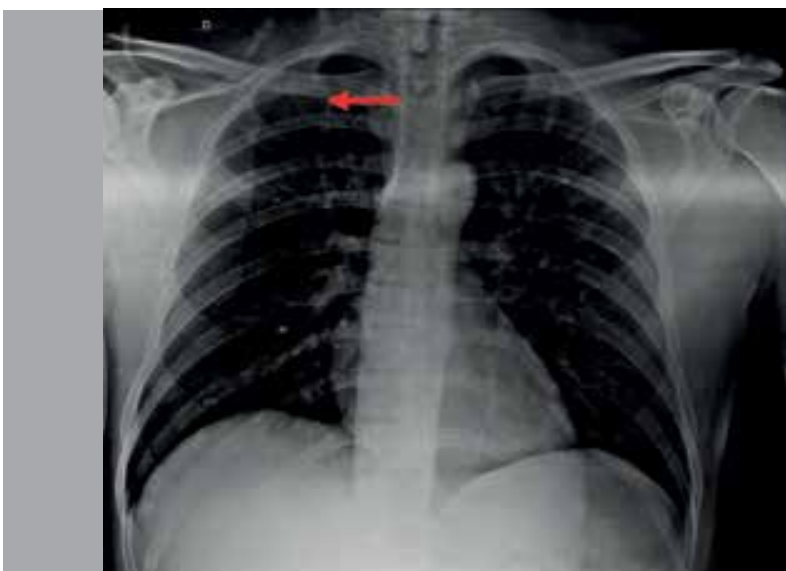

Figure 1. Chest x-ray showing the tip of the PICC positioned in the subclavian vein.

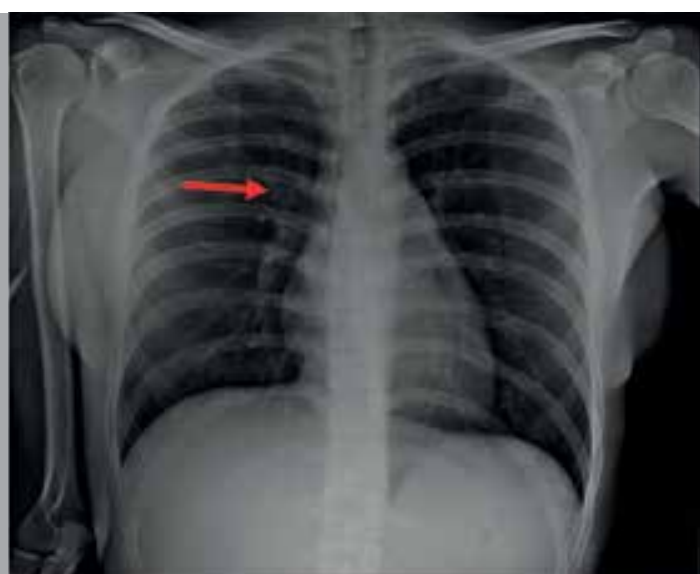

Figure 2. Chest $x$-ray showing the tip of the PICC positioned in the superior vena cava.

\section{MATERIALS AND METHODS}

This retrospective cross-sectional study was conducted at the Institute of Orthopedics and Traumatology of the Hospital das Clínicas da Faculdade de Medicina da Universidade de São Paulo (IOT HC FMUSP), approved by the institutional review board (process 13542). We examined the medical records of patients who were treated with PICCs between 2007 to 2017. Of the 1057 medical records pertaining to patients whose treatment included PICC, 34 were excluded for not having complete data for subsequent analysis. A total of 1023 patient records were included. All PICCs were inserted by certified nurses trained in insertion of this catheter. All patients agreed to receive intravenous therapy via PICC and signed an informed consent form. The Intravenous Therapy Group at our institute developed an algorithm which uses the time of intravenous therapy and the characteristics of the drugs prescribed as criteria for selecting central devices. (Figure 3) The following data were obtained from the medical records: age, sex, diagnosis, date of PICC insertion, indication for insertion, type of puncture performed, vein punctured, number of punctures performed, positioning of catheter tip, medications administered, complications related to the use of the catheter, reason for removing the catheter, date of PICC removal, and PICC duration. All catheters used were made of silicone, $4 \mathrm{Fr}$, and had a single lumen and anti reflux valve. PICCs were inserted via direct puncture or guided by US. PICCs were installed at the patient's bedside, using the maximal barrier technique to establish a sterile field. For safety purposes, the procedures were performed by two nurses, which is the normal practice in our institution. Children under 13 years were sedated in the surgical center in order to perform the procedure. The basilic, cephalic or the veins of the antecubital fossa were punctured. The anatomic measurements were made before starting the procedure. In accordance with the manufacturer's instructions, the nurse measured the distance from the puncture site to the anterior axillary fold, from the anterior axillary fold to the head of the right clavicle, and from the head of the right clavicle to the right edge of the sternum in the third intercostal space. Even if the puncture is made in the left arm, the distance to the head of the right clavicle should still be measured. (Figure 4) After the procedure, all patients underwent chest x-rays to confirm the placement of the catheter tip. The catheter was considered properly positioned when the tip of the PICC was located in the superior vena cava, and poorly positioned when the tip of the catheter was in the peripheral veins or the subclavian vein. Catheters positioned in the atrium or in the jugular vein were repositioned, and an additional chest $x$-ray was taken. Only the final positioning was considered. The quantitative characteristics were described using summary measures (mean, standard deviation, median, minimum and maximum) and the qualitative characteristics were described using absolute and relative frequencies. ${ }^{14}$ The data were analyzed with SPSS for Windows version 20.0 software, and Microsoft Excel 2008 was used to tabulate the data.

\section{RESULTS}

The study population $(n=1023)$ was $75.5 \%$ men $(n=772)$ and $24.5 \%$ women $(n=251)$. The median age was $42.4 \pm 18.3$ years. The most frequent diagnoses of patients who received PICCs were: postoperative infection of the lower limbs (39\%), postoperative infection of the upper limbs (14\%), open fractures (12\%), and multiple trauma (89\%). (Table 1) As for veins punctured, $51.6 \%$ of the PICCs were inserted in the basilic vein, $38.3 \%$ in the cephalic vein, and $10.10 \%$ in the veins of the antecubital fossa. In terms of insertion technique, $82.7 \%$ of PICCs were inserted via direct puncture and $17.3 \%$ were guided by ultrasound. We observed that $70.4 \%$ of the catheters were properly positioned, while $29.6 \%$ of PICCs were improperly positioned. PICC was properly inserted after the first 


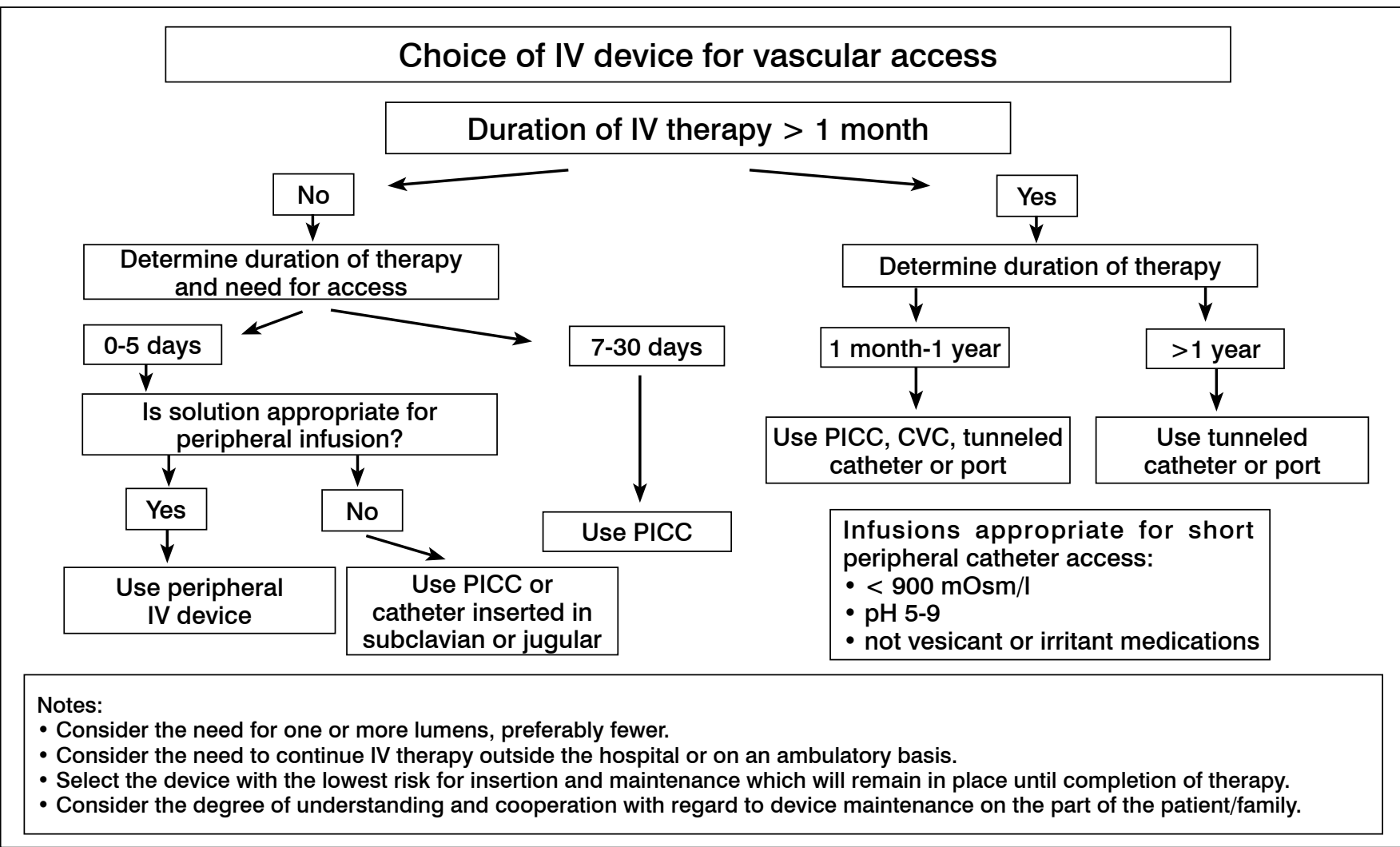

Figure 3. Algorithm for intravenous device selection.

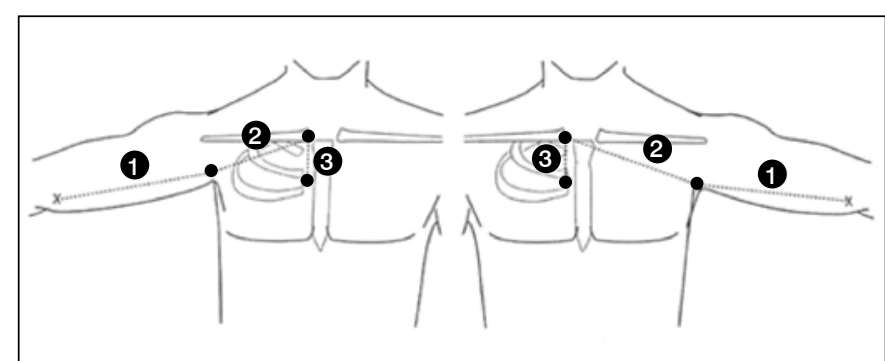

Figure 4. Measurements taken prior to procedure for proper positioning of the PICC

Table 1. Distribution of patients receiving PICC, by diagnosis.

\begin{tabular}{c|c|c}
\hline Diagnosis & $\mathbf{n}$ & $\%$ \\
\hline Postoperative infection (upper limbs) & 403 & 39 \\
\hline Postoperative infection (lower limbs) & 140 & 14 \\
\hline Open fracture & 120 & 12 \\
\hline Multiple trauma & 88 & 9 \\
\hline Clinical complications & 74 & 7 \\
\hline Chronic osteomyelitis & 67 & 7 \\
\hline Postoperative infection (pelvic ring) & 45 & 4 \\
\hline Pyoarthritis & 34 & 3 \\
\hline Postoperative infection (spine) & 21 & 2 \\
\hline Tumor & 14 & 1 \\
\hline Amputation & 11 & 1 \\
\hline Spondylodiscitis & 6 & 1 \\
\hline
\end{tabular}

puncture in $89.7 \%$ of cases, the second puncture in $5.7 \%$ of cases, the third in $2.6 \%$ of cases, the fourth in $1.3 \%$ of cases, the fifth in $0.4 \%$ of cases, and the sixth in $0.3 \%$ of cases. The main indication was antibiotic therapy. The most commonly used antibiotics in treating patients who used PICC were teicoplanin, prescribed in $47.8 \%$ of cases (487 patients), followed by amikacin, prescribed in $26.2 \%$ of cases (267 patients), clindamycin in $22.5 \%$ of cases (229 patients), and gentamicin in $17.8 \%$ of cases (181 patients). (Table 2) As for the number of antibiotics prescribed to the same patient, 671 patients $(65.85 \%)$ were treated with two antibiotics, 44 patients (4.32\%) used three antibiotics, 11 patients (1.08\%) used four antibiotics, and one patient $(0.1 \%)$ used nine different antibiotics. The patients maintained PICCs for a mean time of 34.3 days; the maximum duration was 414 days. The reasons for PICC removal were: completion of treatment (77.3\%), catheter malfunction (5.7\%), medical indication (4.6\%), accidental removal (2.4\%), death (1\%), phlebitis $(0.7 \%)$, removed during surgery to approach the limb $(0.6 \%)$, and allergic reaction (0.4\%). Discharge with PICC $(7.3 \%)$ is not a reason for withdrawal, but is presented to differentiate patients who completed intravenous therapy in our institute from those who completed therapy in other health services. (Table 3)

\section{DISCUSSION}

Most of the studies describes the uses of PICCs in pediatric patients, cancer patients, or patients in intensive care units. ${ }^{15-19}$ Few studies for exclusively orthopedic patients are found in literature, as this series of 1023 cases does. This fact grants this study importance for addressing the use of PICCs in a different group of patients. Valbousquet Schneider et al. ${ }^{16}$ conducted a retrospective study with 136 orthopedic patients in a military hospital in France from 2009 to 2014. A total of 180 PICCs were inserted using ultrasound-guided puncture. The average duration of the catheter was 21 days. The 
Table 2. Antibiotics most frequently used and infused via PICC.

\begin{tabular}{|c|c|c|}
\hline ATB, $n(\%)$ & $\mathrm{n}$ & $(\%)$ \\
\hline Teicoplanina & 487 & $47.8 \%$ \\
\hline Amicacina & 267 & $26.2 \%$ \\
\hline Clindamicina & 229 & $22.5 \%$ \\
\hline Gentamicina & 181 & $17.8 \%$ \\
\hline Ceftriaxona & 94 & $9.2 \%$ \\
\hline Ciprofloxacina & 85 & $8.3 \%$ \\
\hline Ceftazidima & 75 & $7.4 \%$ \\
\hline Oxacilina & 69 & $6.8 \%$ \\
\hline Meropenem & 43 & $4.2 \%$ \\
\hline Vancomicina & 42 & $4.1 \%$ \\
\hline Colistina & 39 & $3.8 \%$ \\
\hline Ertapenem & 32 & $3.1 \%$ \\
\hline Ampicilina & 28 & $2.7 \%$ \\
\hline Tigeciclina & 23 & $2.3 \%$ \\
\hline Cefazolina & 19 & $1.9 \%$ \\
\hline Sulbactam & 13 & $1.3 \%$ \\
\hline Linezolida & 12 & $1.2 \%$ \\
\hline Fluconazol & 12 & $1.2 \%$ \\
\hline Imipenem & 12 & $1.2 \%$ \\
\hline Metronidazol & 11 & $1.1 \%$ \\
\hline Levofloxacina & 10 & $1.0 \%$ \\
\hline Piperacilina & 9 & $0.9 \%$ \\
\hline Cefepime & 9 & $0.9 \%$ \\
\hline Tazobactam & 8 & $0.8 \%$ \\
\hline Penicilina & 2 & $0.2 \%$ \\
\hline Daptomicina & 2 & $0.2 \%$ \\
\hline Sulfametoxazol & 1 & $0.1 \%$ \\
\hline Azitromicina & 1 & $0.1 \%$ \\
\hline Voriconazol & 1 & $0.1 \%$ \\
\hline Claritromicina & 1 & $0.1 \%$ \\
\hline Trimetropim & 1 & $0.1 \%$ \\
\hline Amoxicilina & 1 & $0.1 \%$ \\
\hline
\end{tabular}

* Most of the patients used more than one antibiotic.

Table 3. Distribution of patients receiving PICC according to reason for catheter removal.

\begin{tabular}{c|c|c}
\hline Reason for removal, $\mathbf{n}(\%)$ & $\mathbf{n}$ & $\%$ \\
\hline Completion of treatment & 791 & 77.3 \\
\hline Discharged with the catheter & 75 & 7.3 \\
\hline Occlusion & 58 & 5.7 \\
\hline Medical indication & 47 & 4.6 \\
\hline Accidental removal & 25 & 2.4 \\
\hline Death & 10 & 1 \\
\hline Phlebitis & 7 & 0.7 \\
\hline Removed during surgery & 6 & 0.6 \\
\hline Allergic reaction & 4 & 0.4 \\
\hline
\end{tabular}

most frequent diagnosis was osteomyelitis. Sixty-four percent of patients had the catheter removed at the end of the treatment. In 2015, Park et al. ${ }^{17}$ analyzed 4,101 PICCs inserted by direct puncture in a tertiary hospital in Korea from 2002 to 2010. These authors reported that $33.6 \%$ of the patients were attended by the oncology department, $13.3 \%$ by internal medicine, $9.8 \%$ by general surgery, and $8 \%$ by orthopedic surgeons. As for indication, $5 \%$ of the catheters were placed for antibiotic therapy, 3.2\% for chemotherapy, $2.9 \%$ for parenteral nutrition, and $88 \%$ for venous access. The basilic vein was punctured in $65.9 \%$ of cases, followed by the cephalic vein in $30.9 \%$, and the median antecubital fossa in $3.2 \%$ of cases. The catheter remained in place until the end of the treatment in $61.5 \%$ of the patients, and was removed in $23.8 \%$ of cases because of complications. In this study, 1023 PICCs were inserted between 2007 and 2017. Seventy-five per cent of patients were male and the mean age was 42.4 years (SD: 18.3). Direct puncture (82.7\%) and ultrasound-guided puncture (17.3\%) were used to insert the PICCs. The average time patients retained the catheter was 34.3 days. The most frequent diagnosis was postoperative infection of the lower limbs. The most frequently punctured vein was the basilica, in $51.6 \%$ of the cases. Seventy-seven per cent of hospitalized patients remained until the end of their treatment with the catheter, and $7.3 \%$ of the patients were discharged with the catheter to complete treatment on an outpatient basis. A study by Sainathan et al. ${ }^{20}$ showed that of the 700 PICCs inserted, $48.7 \%$ were indicated for prolonged antibiotic treatment, $22.3 \%$ for difficult peripheral venous access, and the rest divided between patients in the intensive care unit, infusion of irritating medications, and outpatient treatment. In the present study, 92.8\% of PICCs were inserted for antibiotic therapy and $7.2 \%$ were inserted to treat clinical complications. The most frequent diagnoses were postoperative infection of the lower limbs (39.4\%), followed by postoperative infection of the upper limbs (13.7\%), open fractures (11.7\%), and multiple trauma (8.6\%). The most commonly used antibiotics were teicoplanin (47.8\%), amikacin (26.2\%), clindamycin (22.5\%), and gentamicin (17.8\%). We also reported that $71.34 \%$ of patients received more than one antibiotic. Teicoplanin has a pH similar to blood (7.35-7.45), while the others are more acidic, and when acidic drugs are infused into the peripheral veins they cause histological changes in the vessel walls; consequently, chemical phlebitis may be a complication. ${ }^{21}$ For this reason, it is essential to understand the characteristics of the prescribed drugs. In a 2007 study, Trerotola et al. ${ }^{22}$ analyzed the positioning of PICC tips placed at the patient bedside. The X-rays were interpreted by radiologists who used the angle of the right cephalic trunk as a reference for the origin of the superior vena cava and the rounded portion of the upper part of the right atrium junction to estimate the cavo-atrial junction. Of the 1,654 catheters inserted, 163 (10\%) were poorly positioned. The statistical analysis showed that the vein punctured was related to poor placement, with the cephalic vein (16\%) presenting the greatest association. Venkatesan et al. ${ }^{23}$ used the carina as a reference to evaluate the placement of the PICC tip. The catheter was considered properly positioned when the tip was $3-5 \mathrm{~cm}$ below the carina. In this study, of the 215 PICCs analyzed, only $37 \%$ were properly positioned. In this study, the lower portion of the superior vena cava or the cavo-atrial junction were used as references for as ideal positioning, in accordance with the recommendations of the Infusion Nurse Society (INS) and the National Association of Vascular Access Networks (NAVAN). ${ }^{24}$ The anatomical reference was the third posterior intercostal space, located via an anteroposterior chest $x$-ray. Of the 1023 catheters inserted, $70.4 \%$ were adequately placed and $29.6 \%$ were incorrectly positioned. This study only considered the final positioning of the catheter tip after any repositioning maneuvers (when necessary). As for infection, Liscynesky et $a l .{ }^{25}$ reported that $5 \%$ of PICCs were 
removed because of this complication. These authors also reported that $4 \%$ of PICCs were unnecessarily removed because of suspected infection, confirmed by negative blood cultures. In 2013, Chopra et al. ${ }^{26}$ published a systematic review of 1185 studies to compare the rate of infection of PICC versus central venous catheters (CVC). Of the 1185 studies, 23 met the inclusion criteria. Of the 23 included publications, 20 reported infection as a complication in PICC and CVC. The authors concluded that the rate of infection in patients who used PICC for intravenous therapy was lower than in patients who utilized CVC. In this study, 5.7\% of the catheters were removed by medical recommendation because of suspected infection. After samples from all the removed catheter tips and the patient's peripheral blood were cultured, no cases of catheter-related infection were confirmed. The low rate of complications found in this study may be associated with less severe clinical condition of orthopedic patients and the choice of a smaller caliber PICC with a single lumen (4 Fr). Finally, this is the first study in our region that reports the use of PICC exclusively in orthopedic patients, and is also one of the few in literature that evaluates the benefits and complications of this catheter in this group of patients. The low rate of complications reported, especially for thrombosis and infection (which generate great concern related to the use of this catheter and were not observed in this study) differentiate this study from other publications

\section{CONCLUSION}

The peripherally inserted central catheter is an intravenous device which is safe and suitable for medium- and long-term intravenous therapy in hospitalized or discharged orthopedic patients.

AUTHORS' CONTRIBUTIONS: Each author made significant individual contributions to this manuscript. TQS (0000-0003-1314-7573) ${ }^{\star}$, AMB $(0000-0002-$ 0830-4602) ${ }^{*}$, AMMG (0000-0003-0079-2733)*, JPZ (0000-0001-5941-7714)*, and OPC (0000-0002-1128-7292)*: were the main contributors in writing this manuscript; TQS participated in developing the concept, research, design, drafting the article, and the analysis. AMB participated in developing the concept, research, drafting the article, and data collection; AMMG participated in developing the concept, research, drafting the article, and the analysis; JPZ participated in developing the concept, research, design, and data collection; OPC participated in developing the concept, drafting the article, and the analysis. All the authors approved the final version of this manuscript. *ORCID (Open Researcher and Contributor ID).

\section{REFERENCES}

1. Costa LC, Paes GO. Aplicabilidade dos diagnósticos de enfermagem como subsídios para a indicação do cateter central de inserção periférica. Esc Anna Nery. 2012;16(4):649-56.

2. Santolim TQ, Santos LA, Giovani AM, Dias VC. The strategic role of the nurse in the selection of IV devices. Br J Nurs. 2012;21(21):S28, S30-2.

3. Ajenjo MC, Morley JC, Russo AJ, McMullen KM, Robinson C, Williams RC et al. Peripherally inserted central venous catheter-associated bloodstream infections in hospitalized adult patients. Infect Control Hosp Epidemiol. 2011;32(2):125-30.

4. Lopes OP, Ribas RD, Giovani AMM, Santolim TQ, Carlos AM, Carvalho MK et al. Evaluation of the use of peripherally inserted central catheters in orthopedic patients at the day Hospital of University of São Paulo. JAVA. 2014;19(3):180-7.

5. Jesus VCd, Secoli SR. Complicações acerca do cateter venoso central de inserção periférica (PICC). Cienc Cuid Saúde. 2007;6(2):252-60.

6. Moureau NL. It's all about PICCs. Optimal catheter and vein selection prove vital to patient safety initiatives. Nursing Management. 2006;37(5):22-7.

7. Horattas MC, Trupiano J, Hopkins S, Pasini D, Martino C, Murty A. Changing concepts in long-term central venous access: catheter selection and cost savings. Am J Infect Control. 2001;29(1):32-40.

8. Parkinson R, Gandhi J, Harper J, Archibald C. Establishing an ultrasound guided peripherally inserted central catheter (PICC) insertion service. Clin Radiol. 1998;53(1):33-6.

9. Marculescu CE, Berbari EF, Cantey JR, Osmon DR. Practical considerations in the use of outpatient antimicrobial therapy for musculoskeletal infections. Mayo Clin Proc. 2012;87(1):98-105

10. Pittiruti M, Scoppettuolo G, La Greca A, Emoli A, Brutti A, Mogliorini I. The EKG method for positioning the tip of PICCs: results from two preliminary studies. JAVA. 2008;13(4):179-86.

11. York N. The importance of ideal central venous access device tip position. $\mathrm{Br}$ J Nurs. 2012;21(21):S19-20, S22, S24.

12. Johnston AJ, Bishop SM, Martin L, See TC, Streater CT. Defining peripherally inserted central catheter tip position an evaluation of insertions in one unit. Anaesthesia. 2013;68(5):484-91.

13. Moureau NL, Dennis GL, Ames E, Severe R. Eletrocardiogram (EKG) guided peripherally inserted central catheres placement and tip position: results of a trial to replace radiological confirmation. JAVA. 2010;15(1):8-14.

14. Kirkwood BR, Sterne JAC. Essential medical statistics. 2ed. Massachusetts: Backwell Science; 2006.
15. Cotogni P, Barbero C, Garrino C, Degiorgis C, Mussa B, De Francesco A et al. Peripherally inserted central catheters in non-hospitalized cancer patients: 5-year results of a prospective study. Support Care Cancer. 2015;23(2):403-9.

16. Valbousquet Schneider L Jr, Duron S, Arnaud FX, Bousquet A, Kervella Y, Bouzad C et al. Evaluation of PICC complications in orthopedic inpatients with bone infection for long-term intravenous antibiotics therapy. J Vasc Access. 2015;16(4):299-308.

17. Park JY, Kim HL. A comprehensive review of clinical nurse specialist - led peripherally inserted central catheter placement in Korea. J Infus Nurs. $2015 ; 38(2): 122-8$.

18. Leroyer C, Lashéras A, Marie V, Le Bras Y, Carteret T, Dupon M et al. Prospective follow-up of complications related to peripherally inserted central catheters. Med Mal Infect. 2013;43(8):350-5.

19. Kelly L. A practical guide to safe PICC placement. Br J Nurs. 2013;22(8):S13-4, S16, S18-9.

20. Sainathan S, Hempstead M, Andaz S. A single institution experience of seven hundred consecutively placed peripherally inserted central venous catheters. J Vasc Access. 2014;15(6):498-502.

21. Arreguy-Sena C, Carvalho EC. Risk for vascular trauma: diagnosis proposal and validation by experts. Rev Bras Enferm. 2009;62(1):71-8.

22. Trerotola SO, Thompson S, Chittams J, Vierregger KS. Analysis of tip malposition and correction in peripherally inserted central catheters placed at bedside by a dedicated nursing team. J Vasc Interv Radiol. 2007;18(4):513-8.

23. Venkatesan T, Sen N, Korula PJ, Surendrababu NR, Raj JP, John P et al. Blind placements of peripherally inserted antecubital central catheters: initial catheter tip position in relation to carina. Br J Anaesth. 2007;98(1):83-8.

24. Naylor CL. Reduction of malposition in peripherally inserted central catheters whit tip locations system. JAVA. 2007;12(1):29-31.

25. Liscynesky C, Johnston J, Haydocy KE, Stevenson KB. Prospective evaluation of peripherally inserted central catheter complications in both inpatient and outpatient settings. Am J Infect Control. 2017;45(9):1046-9.

26. Chopra V, O'Horo JC, Rogers MA, Maki DG, Safdar N. The risk of bloodstream infection associated with peripherally inserted central catheters compared with central venous catheters in adults: a systematic review and meta-analysis. Infect Control Hosp Epidemiol. 2013;34(9):908-18. 